ISSN 2306-1561

Automation and Control in Technical Systems (ACTS)

2014, No 1.2(9), pp. 143-148.

DOI: $10.12731 / 2306-1561-2014-1-27$

\title{
Organizational culture as a factor in increasing the efficiency of personnel
}

\section{Nikolaeva Galina Nikolaevna}

Russian Federation, Ph. D., Associate Professor, Department of «Sociology and Management».

State Technical University -MADI, 125319, Russian Federation, Moscow, Leningradsky prospekt, 64. Tel.: +7 (499) 151-64-12. http://www.madi.ru

\section{nikol-galina@yandex.ru}

\begin{abstract}
The author raises the question of the need to consider the organizational culture of the enterprise as a factor in increasing the efficiency of the staff of the enterprise. Each type of organizational culture is characterized by a set of specific management practices, and leaders give priority in the selection of methods to influence staff differently. Need a combination of management practices, so that the result of the impact on staff was the most effective.
\end{abstract}

Keywords: organizational culture of the enterprise, the efficiency of the staff, administrative, economic, social and psychological methods of personnel management. 
ISSN 2306-1561

Автоматизация и управление в технических системах (АУТС) 2014. - №1.2(9). - C. 143-148.

DOI: $10.12731 / 2306-1561-2014-1-27$

\section{УДК 377.4}

\section{Организационная культура как фактор повышения эффективности работы персонала}

\section{Николаева Галина Николаевна}

Российская Федерация, кандидат экономических наук, доцент кафедры «Социологии и управления».

ФГБОУ ВПО «Московский автомобильно-дорожный государственный технический университет (МАДИ)», 125319, Российская Федерация, г. Москва, Ленинградский проспект, д.64, Тел.: +7 (499) 151-64-12, http://www.madi.ru

\section{nikol-galina@yandex.ru}

Аннотация. Автор ставит вопрос о необходимости рассматривать организационную культуру предприятия как фактор повышения эффективности работы персонала данного предприятия. Каждый из типов организационной культуры характеризуется набором определенных методов управления, и руководители отдают приоритетность в выборе методов воздействия на персонал по-разному. Необходимо такое сочетание методов управления, чтобы результат этого воздействия на персонал был наиболее эффективным.

Ключевые слова: организационная культура предприятия, эффективность работы персонала, административные, экономические, социальные и психологические методы управления персоналом.

\section{1. Введение}

Социально-экономические особенности начала XXI века, стремление организаций к эффективной деятельности, в центре внимания отечественного менеджмента ставят человеческий фактор. В современных условиях глобальной конкуренции и стремительного устаревания продуктов и технологии, сотрудники организации являются одним из основных факторов, определяющих ее успех в долгосрочной перспективе.

Управляющее воздействие во всех сферах деятельности предприятия происходит при неизбежном столкновении с культурой организации. С учетом рассмотренных в научной литературе подходов, моделей, типов и взглядов на организационную культуру, следует отметить, что цели для ее изучения различны. К ним относятся 
выявление доминирующей организационной культуры, влияние культуры на внутриорганизационные процессы, исследование социально - экономического пространства конкретного предприятия и др. В настоящее время в научной литературе часто рассматривается вопрос, увязывающий развитие организационной культуры с эффективностью работы персонала предприятия.

Следует отметить, что каждый из типов организационной культуры характеризуется набором определенных методов управления, и руководители отдают приоритетность в выборе методов воздействия на персонал по-разному [1, 3, 10 - 12]. Максимальные различия в выборе методов наблюдаются на этапах жизненного цикла предприятия. На этапе формирования предприятия (или упадка), безусловно, при использовании набора методов, преобладать будут административные методы управления. На этапе роста и взросления организации усиливается применение экономических методов управления персоналом. А на этапе зрелости закономерно возникает необходимость анализа выбранных методов управления, с целью поиска резервов роста эффективности всей управленческой деятельности.

Часто складывается ситуация, что раннее выбранные методы управления становятся нормой управленческой деятельности, и на новых этапах развития организации не всегда способствуют достижению необходимых результатов и показателей эффективности. Нами обоснована целесообразность применения методов управления персоналом для исследования влияния организационной культуры на эффективность работы сотрудников. Административные, экономические, социальные и психологические методы являются способами воздействия на персонал для достижения целей организации. В то же время методы управления персоналом являются и проявлениями культуры, следовательно, они будут индикаторами обратного влияния, т.е. формирования культуры организации.

\section{2. Модели и методы}

Необходимо такое сочетание методов управления, чтобы результат этого воздействия на персонал был наиболее эффективным. Если рассматривать эффективность работы персонала персоналом $\left(Э_{\text {рп }}\right)$ в виде функции $f(X)$ с позиций значимости различных факторов, которые выступают в роли условных переменных $\left(x_{1}, x_{2}, x_{3}, \ldots x_{n}\right)$, то можно утверждать [1]: $\ni_{\text {рп }}=f(X)$,

где $X=\left\{x_{1}, x_{2}, x_{3}, x_{4}, x_{5}, x_{6} \ldots x_{n}\right\}$,

$x_{1}$ - средства и условия труда;

$x_{2}$ - предметы труда, их стоимость и качество;

$x_{3}$ - технология производственной деятельности;

$x_{4}-$ уровень организации труда и контроль;

$x_{5}$ - организационная культура предприятия;

$x_{6}$ - мотивация и стимулирование труда;

$x_{n}-$ другие факторы. 
Организационная культура, являясь одним из важнейших факторов в развитии предприятия, определяет политику в области управления человеческими ресурсами. Она тогда эффективна, когда служит интересам предприятия и каждого отдельного работника. На сегодняшний момент это особенно актуально, т.к. в этом заинтересованы не только предприятия, и люди, работающие на них, но и общество в целом.

Практическая значимость представленных утверждений заключается в том, что формирование организационной культуры должно осуществляться под пристальным вниманием руководителей и служб управления персоналом с целью поиска резервов роста эффективности в деятельности работников предприятия.

Важно уметь различать понятия декларируемой и реальной культуры. Первая существует только на бумаге и представляет собой желаемое состояние вещей. Реальная культура, может быть как близкой по духу декларируемой, так и резко с ней контрастирующей. Здесь следует выделять понятие субкультуры (культура в культуре), которая включает ряд ценностей доминирующей культуры и добавляет к ним новые ценности, характерные только для нее.

\section{3. Результаты}

Культура предприятия, продекларированная руководством, должна способствовать эффективному развитию предприятия (эволюционному пути), но она не всегда полностью принята персоналом предприятия. Задача менеджера - организатора заключается в том, чтобы в нужный момент найти «параметры порядка» в проявлении культуры, которые обеспечили бы положительную динамику показателей эффективности, и «параметры беспорядка», для выявления направлений совершенствования работы, которые формируют организационную культуру [3]. Необходимо запустить процесс самоорганизации культуры предприятия (рисунок 1) [2].

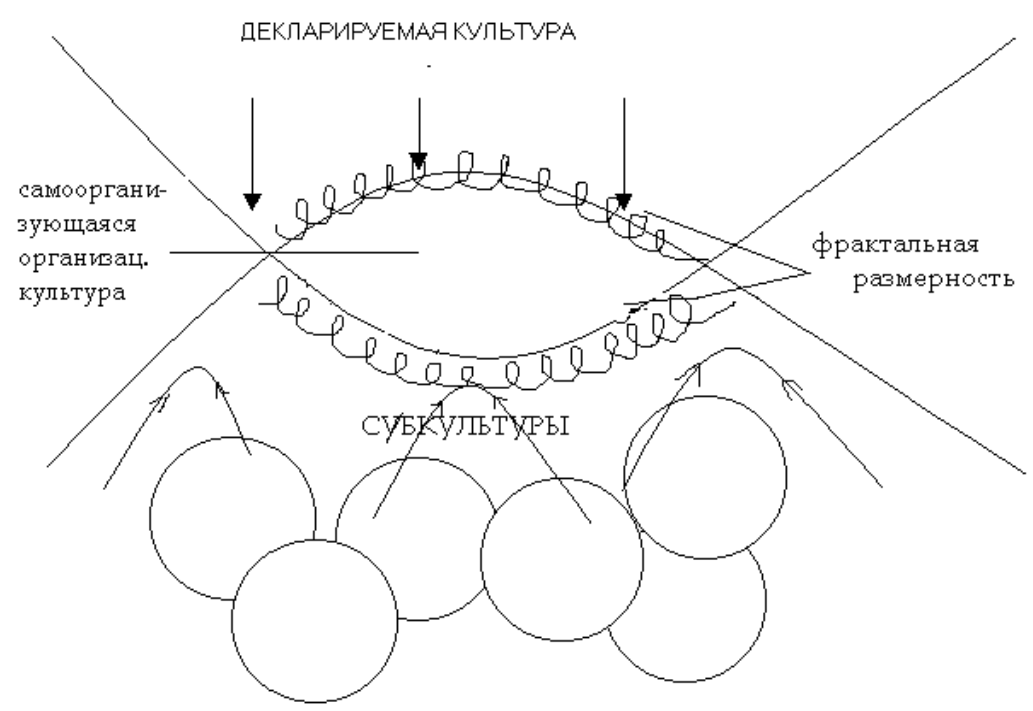

Рисунок 1 - Процесс самоорганизации культуры предприятия 


\section{4. Обсуждение}

Беспорядок, или хаос, всегда вызывал большие опасения, чем порядок. Синергетический подход разрушает стереотип страха перед хаосом и превращая его в поле, рождающее нововведения. Другими словами, надо понять, как способствовать собственным тенденциям развития системы.

Центральная идея синергетики - это самоорганизация сложных, открытых и нелинейных систем. О самоорганизации культуры предприятия, как сложной системы говорят многие авторы, рассматривая самоорганизацию как механизм приспособления к внутриорганизационным изменениям и к внешним воздействиям.

Открытость системы в традиционном подходе характеризуются взаимодействием с внешней средой (на входе и выходе системы). Синергетика определяет открытость не в локальном источнике, а в каждой точке системы. Следовательно, открытость организационной культуры начинается с отдельной личности. Это существенным образом отличает открытую систему, рассматриваемую при синергетическом подходе, от открытой системы, рассматриваемой в традиционном подходе.

Открытость системы - необходимое, но не достаточное условие для ее самоорганизации. Самоорганизующаяся система всегда открыта, но не всякая открытая система начинает процесс самоорганизации. Нелинейность - основа синергетического подхода. Она означает многовариантность путей развития и необратимость этих процессов. Система выбирает тот путь развития, который ей позволяет быть устойчивой, но это необязательно эволюционный путь.

Новое понимание открытости и нелинейность организационной культуры показывает не только возможность, но и необходимость ее исследования с позиции синергетики. Практическая значимость использования синергетического подхода в исследовании организационной культуры заключается в том, что она позволяет получить дополнительную информацию, анализ которой поможет разработать мероприятия по формированию эффективной организационной культуры [2].

\section{5. Заключение}

В результате обоснования целесообразности изучения культуры предприятия через призму методов управления, возможности ее исследования с позиции синергетики, и с учетом имеющихся в научной литературе подходов было получено определение организационной культуры, которое отражает ее место в процессе развития предприятия. Организационная культура - это сложная, нелинейная, открытая, самоорганизующаяся система, обеспечивающая мотивацию персонала и регулирование деятельности предприятия, с учетом норм, ценностей, правил и методов управления, разделяемых и применяемых большинством работников, и являющаяся фактором эффективной работы персонала организации. 


\section{Список информационных источников}

[1] Николаева Г. Н. Развитие организационной культуры - фактор повышения эффективности работы персонала: дис. ... канд. экон. наук / Г.Н. Николаева; Байкальский государственный университет экономики и права. - Иркутск, 2006 г. $214 \mathrm{c}$.

[2] Николаева Г.Н. Синергетический подход к изучению организационной культуры // Наука и производство-2009: междунар.науч.-практ. конф., Брянск: БГТУ, 2009.Ч.2. С.319-322.

[3] Николаева Г.Н. Синергетический подход к поиску путей выхода из кризиса на микроуровне // Онтология кризиса в пространстве и времени человека: сборник материалов междисциплинарной научной конференции молодых ученых и специалистов - Самара: Порто-принт, 2009. С.46-49.

[4] Николаева Г.Н. Эффективность работы персонала и организационная культура // Проблемы управления безопасностью сложных систем: Труды XX Международной конференции, Москва, 01-31 декабря 2012. М.: РГГУ, 2012. С. 71-75.

[5] Ахтеров А.В., Шастина А.Е., Лезина О.В. Диагностика развития организационноуправленческих компетенций инженеров с помощью самоорганизующихся карт Кохонена // Автоматизация и управление в технических системах. - 2013. - № 4.2. C. 35-45. DOI: 10.12731/2306-1561-2013-4-28.

[6] Akhterov A.V., Lezina O.V., Shastina A.E. Diagnostics of development of organizational and managerial competencies of the engineers using the self-organizing Kohonen maps // International Journal of Advanced Studies - 2013. Vol.3. No 4. pp. 2833. DOI: $10.12731 / 2227-930 X-2013-4-6$.

[7] Ахтеров А.В., Лезина О.В., Федоров И.В. Информационно-аналитическая образовательная платформа вуза для интеграции учебного процесса в области менеджмента // В мире научных открытий. 2012. № 2.6 (26). С. 144-158.

[8] Ахтеров А.В. Использование метода самоорганизующихся нейронных сетей для выделения геологических неоднородностей нефтегазоносных пластов // В мире научных открытий. 2012. № 12 (36). С. 32-41.

[9] Ахтеров А.В., Лезина О.В., Федоров И.В. Системная модель информационнообразовательной среды выпускающей кафедры вуза // Вестник Московского автомобильно-дорожного государственного технического университета (МАДИ). 2010. № 1. С. 12a-17.

[10] Исмоилов М.И. Подготовка и переподготовка персонала предприятий промышленного и транспортного комплексов с применением мобильных технологий: монография / М.И. Исмоилов, А.Б. Николаев, А.В. Остроух. - SaintLouis, MO, USA: Publishing House Science and Innovation Center, 2013. - 166 c. ISBN 978-0-615-67111-6.

[11] Ostroukh A.V., Barinov K.A., Surkova N.E. Formulation of business games for training and retraining of industrial enterprises // Международный журнал экспериментального образования. - 2014. - № 2 - С. 75-78.

[12] Ostroukh A.V., Barinov K.A., Surkova N.E. Computer scenarios of business games for personnel training at industrial enterprises // Международный журнал экспериментального образования. - 2014. - № 2 - С. 79-83. 